\title{
Polymers Derived from 3,6-Fluorene and Tetraphenylsilane Derivatives: Solution-Processable Host Materials for Green Phosphorescent OLEDs
}

\author{
Huan-Chi Yeh, Chen-Han Chien, Ping-I Shih, Mao-Chuan Yuan, and Ching-Fong Shu* \\ Department of Applied Chemistry, National Chiao Tung University, \\ 300 Hsinchu, Taiwan, Republic of China
}

Received February 21, 2008; Revised Manuscript Received March 25, 2008

\begin{abstract}
We have synthesized two fluorene-based polymeric host materials, $\mathbf{P 1}$ and $\mathbf{P 2}$, through palladiumcatalyzed Suzuki couplings of monomers containing tetraphenylsilane and 3,6-disubstituted fluorene frameworks, respectively. The resultant copolymers exhibited high glass transition temperatures $\left(T_{\mathrm{g}} \geq 215^{\circ} \mathrm{C}\right)$ and excellent thermal stability. The conjugation lengths of polymers $\mathbf{P} 1$ and $\mathbf{P 2}$ were effectively confined through the presence of the 3,6-linkages and silane units in the polymer skeleton. The structural features endowed these copolymers with UV-violet emissions in the solid state, together with high triplet energies $\left(E_{\mathrm{T}}=2.60 \mathrm{eV}\right)$, which were sufficiently high for $\mathbf{P 1}$ and $\mathbf{P 2}$ to serve as appropriate hosts for green-emitting phosphors. In the case of polymer $\mathbf{P 2}$, the incorporation of pendent carbazole groups increased the HOMO level markedly and balanced the rates of charge injection and transportation. Employing P2 doped with green-emitting fac-tris(2-phenylpyridine)iridium as the emissive layer, we fabricated highly efficient polymer light-emitting diodes (32 cd/A, 9.2\%) that exhibited significantly enhanced EL performance relative to that of the system employing P1 (14.5 cd/A, 4.2\%).
\end{abstract}

\section{Introduction}

Because of their potential applications in flat-panel displays and solid-state lighting, ${ }^{1-3}$ polymer light-emitting diodes (PLEDs) have attracted considerable interest since their discovery in $1990 .^{3}$ In addition, polymeric materials have the advantage of allowing inexpensive solution processing techniques, such as spin-coating and printing methods, to be utilized for the preparation of large-area-display devices. ${ }^{4-6}$ With their higher device efficiency, electroluminescent (EL) devices based on phosphorescent emitters are considered to be superior to their fluorescent counterparts. Electrophosphorescent devices can harvest both singlet and triplet excitons, and thus, their internal quantum efficiencies can reach a theoretical level as high as $100 \% .^{7-10}$ Polymeric diodes featuring phosphorescent dyes physically doped into the polymer hosts are of particular interest in commercial applications because of the advantages provided by the ability to tailor the spectrum of the emitted light through the choice of an appropriate low-energy dopant. ${ }^{11-16}$ Although the nonconjugated polymer poly(vinylcarbazole) (PVK) is utilized typically as a polymeric host for the fabrication of electrophosphorescent PLEDs because of its high triplet energy $\left(E_{\mathrm{T}}\right)$ and hole transporting ability, ${ }^{17-21}$ it is a unipolar conductor that transports holes only; hence, for the purpose of balancing charge fluxes, a large amount of an electron transporting material, such as 2-(4-biphenylyl)-5-(4-tert-butylphenyl)-1,3,4oxadiazole (PBD) or 3-(4-biphenylyl)-4-phenyl-5-(4-tert-butylphenyl)-1,2,4-triazole (TAZ), must be admixed with PVK to compensate for the poor ability of the host polymer to transport electrons. ${ }^{22}$ Consequently, these physical blends run the risk of phase separation occurring over time. On the other hand, conjugated polymers such as polyfluorenes (PFs) have been employed successfully as polymeric hosts because of their high photoluminescence efficiencies and high conductivities. ${ }^{23,24}$ Several highly efficient red-emitting phosphorescent PLEDs have been reported that employ PFs as host materials, with iridium or osmium complexes serving as phosphorescent dopants. ${ }^{15,25-27}$ Nevertheless, the PFs have a value of $E_{\mathrm{T}}$ of 2.15 $\mathrm{eV}$, which hampers their application as host polymers for

\footnotetext{
* To whom correspondence should be addressed.
}

yellow-emitting, green-emitting, and other short-wavelength phosphorescent PLEDs; the backward energy transfer from the higher-triplet-energy dopants to the PF hosts results in nonradiative decay from the triplet state of the PFs. ${ }^{24,28,29}$ Recently, a class of carbazole-based polymers, featuring linkage of the carbazole units at the 3- and 6-positions, were reported as promising host materials for green devices when doped with green-emitting iridium complexes. ${ }^{30,31}$ The 3,6-linkage was also applied to fluorene units to obtain wide-band-gap polyfluorene copolymers. ${ }^{32}$ In addition, a UV-emitting conjugated homopolymer, poly(9,9-alkyl-3,6-silafluorene), has also been reported to function as a host for green phosphorescent emitters because of its sufficiently high value of $E_{\mathrm{T}}$. ${ }^{3,34}$

In previous studies, tetraphenylsilane moieties have been incorporated into small molecular host materials to interrupt the extended $\pi$-conjugation through the $\delta$-Si structure to achieve high values of $E_{\mathrm{T}}{ }^{35-38}$ Herein, we report the synthesis and characterization of two fluorene-tetraphenylsilane copolymers, $\mathbf{P 1}$ and $\mathbf{P 2}$ (Scheme 2), in which the fluorene units are connected to the tetraphenylsilane moieties via their 3- and 6-positions to minimize the conjugation path as well as to attain a high triplet energy gap. ${ }^{32}$ In the case of polymer $\mathbf{P 2}$, a carbazole group was functionalized directly at the $\mathrm{C}-9$ position of alternating fluorene unit. Carbazoles, a well-established group of hole-transporting materials, ${ }^{39-41}$ have been incorporated into several polymers to improve their hole injection and transportation properties. ${ }^{42-45}$ Employing P2 doped with a green-emitting iridium complex as the emissive layer, we fabricated highly efficient PLEDs (32 $\mathrm{cd} / \mathrm{A}, 9.2 \%$ ) that exhibited significantly enhanced EL performance relative to that of $\mathbf{P 1}(14.5 \mathrm{~cd} / \mathrm{A}, 4.2 \%)$.

\section{Experimental Section}

Materials. 3,6-Dibromofluorenone (1), ${ }^{46}$ 3,6-dibromo-9,9-bis(4hydroxyphenyl)fluorene (2), ${ }^{46}$ and bis(4-bromophenyl)diphenylsilane $(\mathbf{4})^{47}$ were prepared according to reported procedures. Solvents were dried using standard procedures. All other reagents were used as received from commercial sources, unless stated otherwise.

Characterization. ${ }^{1} \mathrm{H}$ and ${ }^{13} \mathrm{C}$ NMR spectra were recorded on a Bruker-DRX 300 spectrometer. Mass spectra were obtained using a JEOL JMS-HX 110 mass spectrometer. Size exclusion chroma- 
tography (SEC) was performed using a Waters chromatography unit interfaced with a Waters 410 differential refractometer; three $5 \mu \mathrm{m}$ Waters Styragel columns $(300 \times 7.8 \mathrm{~mm})$ were connected in series in order of decreasing pore size $\left(10^{4}, 10^{3}\right.$, and $\left.10^{2} \AA\right)$; THF was the eluent. Standard polystyrene samples were used for calibration. Differential scanning calorimetry (DSC) was performed using a SEIKO EXSTAR 6000DSC unit operated at heating and cooling rates of 20 and $40{ }^{\circ} \mathrm{C} \mathrm{min}-1$, respectively. Samples were scanned from 30 to $300{ }^{\circ} \mathrm{C}$, cooled to $0{ }^{\circ} \mathrm{C}$, and then scanned a second time from 30 to $300{ }^{\circ} \mathrm{C}$. The glass transition temperatures $\left(T_{\mathrm{g}}\right)$ were determined from the second heating scans. Thermogravimetric analysis (TGA) was undertaken using a Perkin-Elmer TGA Pyris 1 instrument. The thermal stabilities of the samples were determined under a nitrogen atmosphere by measuring their weight losses while heating at a rate of $20^{\circ} \mathrm{C} \mathrm{min}-1$. UV-vis spectra were measured using an HP 8453 diode-array spectrophotometer. Photoluminescence spectra were obtained using a Hitachi F-4500 luminescence spectrometer. Cyclic voltammetry (CV) measurements were performed using a BAS $100 \mathrm{~B} / \mathrm{W}$ electrochemical analyzer operated at a scan rate of $50 \mathrm{mV} \mathrm{s}^{-1}$; the solvent was anhydrous acetonitrile, and $0.1 \mathrm{M}$ tetrabutylammonium hexafluorophosphate $\left(\mathrm{TBAPF}_{6}\right)$ was the supporting electrolyte. The potentials were measured against an $\mathrm{Ag} / \mathrm{Ag}^{+}\left(0.01 \mathrm{M} \mathrm{AgNO}_{3}\right)$ reference electrode; ferrocene was the internal standard. The onset potentials were determined from the intersection of two tangents drawn at the rising and background currents of the cyclic voltammogram.

Fabrication of Light-Emitting Devices. Polymer LED devices were fabricated in the following configuration: indium tin oxide (ITO)/poly(styrenesulfonate)-doped poly(3,4-ethylenedioxythiophene) (PEDOT, $35 \mathrm{~nm}$ )/light-emitting layer $(50-70 \mathrm{~nm}) / 1,3,5-$ tris $(N$-phenylbenzimidazol-2-yl)benzene (TPBI, $30 \mathrm{~nm}) / \mathrm{LiF}(1 \mathrm{~nm}) /$ $\mathrm{Al}(100 \mathrm{~nm})$. PEDOT was spin-coated directly onto the ITO glass and dried at $80{ }^{\circ} \mathrm{C}$ for $12 \mathrm{~h}$ under vacuum to improve both the hole injection and the substrate smoothness. The light-emitting layer was spin-coated on top of the PEDOT layer, using toluene as the solvent, and then dried under vacuum for $3 \mathrm{~h}$ at $60{ }^{\circ} \mathrm{C}$. Prior to casting the film, the polymer solution was filtered through a Teflon filter $(0.45 \mu \mathrm{m})$. The TPBI layer, which was grown by thermal sublimation in a vacuum of $3 \times 10^{-6}$ Torr, was used as an electrontransport layer that blocked holes and confined excitons. The cathode $\mathrm{LiF} / \mathrm{Al}(1,100 \mathrm{~nm})$ alloy was subsequently deposited onto the TPBI layer. The current-voltage-luminance characteristics were measured under ambient conditions using a Keithley 2400 source meter and a Newport $1835 \mathrm{C}$ optical meter equipped with an 818 ST silicon photodiode.

3,6-Dibromo-9,9-bis(4-hexyloxyphenyl)-9H-fluorene (M1). Compound 2 (1.30 g, $2.56 \mathrm{mmol})$ was added to a mixture of 1-bromohexane (1.27 g, $7.69 \mathrm{mmol})$ and $\mathrm{K}_{2} \mathrm{CO}_{3}(1.06 \mathrm{~g}, 7.68 \mathrm{mmol})$ in DMF $(20 \mathrm{~mL})$. The mixture was heated at $120^{\circ} \mathrm{C}$ and stirred under nitrogen for $3 \mathrm{~h}$ before being poured into water $(100 \mathrm{~mL})$ and extracted with hexane $(3 \times 50 \mathrm{~mL})$. The combined organic layers were dried $\left(\mathrm{MgSO}_{4}\right)$ and concentrated under reduced pressure. The crude product was purified through column chromatography (EtOAc/hexane, 3:100) to afford M1 (1.20 g, 69.4\%) as a white solid. ${ }^{1} \mathrm{H}$ NMR $\left(300 \mathrm{MHz}, \mathrm{CDCl}_{3}\right): \delta 0.86(\mathrm{t}, J=7.2 \mathrm{~Hz}, 6 \mathrm{H})$, $1.23-1.41(\mathrm{~m}, 12 \mathrm{H}), 1.66-1.75(\mathrm{~m}, 4 \mathrm{H}), 3.85(\mathrm{t}, J=6.6 \mathrm{~Hz}, 4 \mathrm{H})$, $6.71(\mathrm{~d}, J=8.7 \mathrm{~Hz}, 4 \mathrm{H}), 7.01(\mathrm{dd}, J=8.7,1.8 \mathrm{~Hz}, 4 \mathrm{H}), 7.21(\mathrm{~d}$, $J=8.1 \mathrm{~Hz}, 2 \mathrm{H}), 7.37(\mathrm{dd}, J=8.1,1.8 \mathrm{~Hz}, 2 \mathrm{H}), 7.80(\mathrm{~d}, J=1.8$ $\mathrm{Hz}, 2 \mathrm{H}) .{ }^{13} \mathrm{C} \mathrm{NMR}\left(75 \mathrm{MHz}, \mathrm{CDCl}_{3}\right): \delta 14.0,22.6,25.7,29.2$, $31.5,63.7,67.9,114.2,121.5,123.5,127.6,128.9,131.2,136.4$, 140.7, 151.0, 158.1. HRMS (m/z): calcd for $\mathrm{C}_{37} \mathrm{H}_{40} \mathrm{Br}_{2} \mathrm{O}_{2}, 676.1375$; found, 676.1385. Anal. Calcd for $\mathrm{C}_{37} \mathrm{H}_{40} \mathrm{Br}_{2} \mathrm{O}_{2}$ : C, 65.69; H, 5.96. Found: C, 65.86; H, 6.07.

3,6-Dibromo-9-phenyl-9H-fluoren-9-ol (3). The 3,6-dibromofluorenone 1 ( $1.20 \mathrm{~g}, 3.55 \mathrm{mmol})$ was added into a Grignard solution that had been prepared from magnesium powder $(0.10 \mathrm{~g}, 4.12$ $\mathrm{mmol})$ and the corresponding 1-bromobenzene $(0.75 \mathrm{~mL}, 7.13$ $\mathrm{mmol})$ in dry ether $(10 \mathrm{~mL})$. The mixture was heated under reflux overnight and then hydrolyzed with saturated $\mathrm{NH}_{4} \mathrm{Cl}(5 \mathrm{~mL})$ solution, extracted with EtOAc $(3 \times 50 \mathrm{~mL})$, washed with brine, and dried $\left(\mathrm{MgSO}_{4}\right)$. Evaporation of the solvent under reduced pressure yielded the crude product, which was purified through column chromatography (EtOAc/hexane acetate, 1:10) to afford 3 $(1.14 \mathrm{~g}, 77.2 \%)$ as a pale yellow solid. ${ }^{1} \mathrm{H} \mathrm{NMR}\left(300 \mathrm{MHz}, \mathrm{CDCl}_{3}\right)$ : $\delta 7.19(\mathrm{~d}, J=8.1 \mathrm{~Hz}, 2 \mathrm{H}), 7.25-7.35(\mathrm{~m}, 5 \mathrm{H}), 7.40(\mathrm{dd}, J=8.1$, $1.8 \mathrm{~Hz}, 2 \mathrm{H}), 7.77(\mathrm{~d}, J=1.8 \mathrm{~Hz}, 2 \mathrm{H}) .{ }^{13} \mathrm{C} \mathrm{NMR}\left(75 \mathrm{MHz}, \mathrm{CDCl}_{3}\right)$ : $\delta 83.2,123.6,123.9,125.4,126.4,127.9,128.7,132.2,140.6,142.1$, 149.6. HRMS $(\mathrm{m} / \mathrm{z})$ : calcd for $\mathrm{C}_{19} \mathrm{H}_{12} \mathrm{Br}_{2} \mathrm{O}, 413.9255$; found, 413.9256.

3-(3,6-Dibromo-9-phenyl-9H-fluoren-9-yl)-9-octyl-9H-carbazole (M2). 9-octyl-9H-carbazole $(0.27 \mathrm{~g}, 0.97 \mathrm{mmol})$ was added dropwise to a mixture of $\mathbf{3}(0.20 \mathrm{~g}, 0.48 \mathrm{mmol})$ and Eaton's reagent $(0.25 \mathrm{~mL})$ in $\mathrm{CH}_{2} \mathrm{Cl}_{2}(3 \mathrm{~mL})$ at $0{ }^{\circ} \mathrm{C}$, and then the system was stirred under nitrogen for $2 \mathrm{~h}$. The reaction mixture was poured into water $(5 \mathrm{~mL})$ and extracted with EtOAc $(3 \times 50 \mathrm{~mL})$. The combined organic layers were dried $\left(\mathrm{MgSO}_{4}\right)$ and concentrated under reduced pressure. The crude product was purified through column chromatography (hexane) to afford $\mathbf{M} 2(0.20 \mathrm{~g}, 61.5 \%)$ as a white solid. ${ }^{1} \mathrm{H}$ NMR $\left(300 \mathrm{MHz}, \mathrm{CDCl}_{3}\right): \delta 0.85(\mathrm{t}, J=6.9 \mathrm{~Hz}$, $3 \mathrm{H}), 1.23-1.32(\mathrm{~m}, 10 \mathrm{H}), 1.80-1.84(\mathrm{~m}, 2 \mathrm{H}), 4.23(\mathrm{t}, J=7.2$ $\mathrm{Hz}, 2 \mathrm{H}), 7.15(\mathrm{dd}, J=7.2,1.2 \mathrm{~Hz}, 1 \mathrm{H}), 7.24-7.26(\mathrm{~m}, 7 \mathrm{H})$, $7.33-7.43(\mathrm{~m}, 6 \mathrm{H}), 7.82(\mathrm{~s}, 1 \mathrm{H}), 7.88(\mathrm{~d}, J=1.8 \mathrm{~Hz}, 2 \mathrm{H}), 7.93$ $(\mathrm{d}, J=7.8 \mathrm{~Hz}, 1 \mathrm{H}) .{ }^{13} \mathrm{C}$ NMR $\left(75 \mathrm{MHz}, \mathrm{CDCl}_{3}\right): \delta 14.0,22.6$, 27.3, 29.0, 29.1, 29.3, 31.8, 43.1, 65.2, 108.62, 108.68, 118.7, 119.4, $120.4,121.6,122.5,122.7,123.6,125.7,125.9,127.0,127.91$, 127.97, 128.4, 131.2, 134.7, 139.4, 140.8, 140.9, 145.4, 151.1. HRMS $(m / z):[\mathrm{M}+\mathrm{H}]^{+}$calcd for $\mathrm{C}_{39} \mathrm{H}_{35} \mathrm{Br}_{2} \mathrm{~N}$, 675.1136; found, 675.1144. Anal. Calcd for $\mathrm{C}_{39} \mathrm{H}_{35} \mathrm{Br}_{2} \mathrm{~N}$ : C, 69.14; H, 5.21; N, 2.07. Found: C, 69.10; H, 5.10; N, 2.47.

Diphenylbis(4-(4,4,5,5-tetramethyl-1,3,2-dioxaborolan-2-yl)phenyl)silane (M3). Compound 4 (2.00 g, $4.05 \mathrm{mmol})$, bis(pinacolato)diboron (2.56 g, $10.1 \mathrm{mmol})$, KOAc (2.38 g, $23.3 \mathrm{mmol})$, and $\left[1,1^{\prime}\right.$-bis(diphenylphosphino)ferrocene]dichloropalladium(II) $(5.0 \mathrm{mg})$ were dissolved in anhydrous DMF $(15 \mathrm{~mL})$ and heated at $85^{\circ} \mathrm{C}$ overnight. Upon cooling, the mixture was poured into water $(10 \mathrm{~mL})$ and extracted with EtOAc $(3 \times 20 \mathrm{~mL})$. The combined organic layers were dried $\left(\mathrm{MgSO}_{4}\right)$ and concentrated under reduced pressure. The crude product was purified through column chromatography (EtOAc/hexane, 1:100) and recrystallization (hexane) to afford M3 (1.03 g, 43.2\%) as a white solid. ${ }^{1} \mathrm{H}$ NMR $(300 \mathrm{MHz}$, $\left.\mathrm{CDCl}_{3}\right): \delta 1.34(\mathrm{~s}, 24 \mathrm{H}), 7.33-7.45(\mathrm{~m}, 6 \mathrm{H}), 7.53-7.59(\mathrm{~m}, 8 \mathrm{H})$, $7.85(\mathrm{~d}, J=7.2 \mathrm{~Hz}, 4 \mathrm{H}) .{ }^{13} \mathrm{C} \mathrm{NMR}\left(75 \mathrm{MHz}, \mathrm{CDCl}_{3}\right): \delta 24.8$, 83.8, 127.9, 129.6, 133.9, 135.7, 136.4, 137.6. HRMS (m/z): calcd for $\mathrm{C}_{36} \mathrm{H}_{42} \mathrm{~B}_{2} \mathrm{O}_{4} \mathrm{Si}$, 588.3038; found, 588.3002. Anal. Calcd for $\mathrm{C}_{36} \mathrm{H}_{42} \mathrm{~B}_{2} \mathrm{O}_{4}$ Si: C, 73.48; H, 7.19. Found: C, 73.16; H, 6.87.

P1. Aqueous $\mathrm{K}_{2} \mathrm{CO}_{3}(2.0 \mathrm{M}, 0.5 \mathrm{~mL}$ ) and Aliquat 336 (ca. 20 $\mathrm{mg})$ were added to a mixture of $\mathbf{M 1}(70.0 \mathrm{mg}, 103 \mu \mathrm{mol})$ and $\mathbf{M 3}$ $(60.8 \mathrm{mg}, 103 \mu \mathrm{mol})$ in toluene $(1 \mathrm{~mL})$. The mixture was degassed, and tetrakis(triphenylphosphine)palladium $(5 \mathrm{mg}$ ) was added in one portion under $\mathrm{N}_{2}$; the solution was then heated at $110{ }^{\circ} \mathrm{C}$ for $36 \mathrm{~h}$. The end groups were capped by heating the mixture under reflux for $12 \mathrm{~h}$ with benzeneboronic acid $(25.6 \mathrm{mg}, 0.21 \mathrm{mmol})$ and then for $12 \mathrm{~h}$ with bromobenzene $(33.0 \mathrm{mg}, 0.21 \mathrm{mmol})$. The reaction mixture was cooled to room temperature and the crude product precipitated over a mixture of $\mathrm{MeOH}$ and water $(7: 3 \mathrm{v} / \mathrm{v}, 100 \mathrm{~mL})$. The crude polymer was collected, washed with excess $\mathrm{MeOH}$, dissolved in THF, and reprecipitated with MeOH. Finally, the polymer was washed with acetone for $72 \mathrm{~h}$ in a Soxhlet apparatus and then dried under vacuum to give $\mathbf{P 1}(47.0 \mathrm{mg}, 53.6 \%) .{ }^{1} \mathrm{H}$ NMR $\left(300 \mathrm{MHz}, \mathrm{CDCl}_{3}\right): \delta 0.85(\mathrm{br}, 6 \mathrm{H}), 1.27-1.39(\mathrm{~m}, 12 \mathrm{H})$, $1.68-1.72(\mathrm{~m}, 4 \mathrm{H}), 3.85(\mathrm{t}, J=6.0 \mathrm{~Hz}, 4 \mathrm{H}), 6.74(\mathrm{~d}, J=8.7 \mathrm{~Hz}$, $4 \mathrm{H}), 7.15(\mathrm{~m}, J=8.7 \mathrm{~Hz}, 4 \mathrm{H}), 7.37-7.52(\mathrm{~m}, 10 \mathrm{H}), 7.62(\mathrm{~d}, J=$ $7.5 \mathrm{~Hz}, 4 \mathrm{H}), 7.67$ (br, 8H), 8.01 (br, $2 \mathrm{H}) .{ }^{13} \mathrm{C} \mathrm{NMR}(75 \mathrm{MHz}$, $\left.\mathrm{CDCl}_{3}\right): \delta 14.0,22.6,25.7,29.2,31.5,63.8,67.8,114.1,118.9$, 126.3, 126.7, 127.1, 127.9, 129.1, 129.7, 132.9, 134.2, 136.4, 136.9, 137.6, 140.3, 140.4, 142.3, 151.6, 157.9.

P2. Following the procedure described above for the preparation of P1, a mixture of M1 (49.9 mg, $73.8 \mu \mathrm{mol}), \mathbf{M} 2$ (50.0 mg, 73.8 $\mu \mathrm{mol})$, and $\mathbf{M 3}(86.9 \mathrm{mg}, 148 \mu \mathrm{mol})$ was copolymerized to yield P2 (62.0 mg, 49.3\%). ${ }^{1} \mathrm{H}$ NMR (300 MHz, $\left.\mathrm{CDCl}_{3}\right)$ : $\delta 0.88$ (br, 9H), $1.22-1.41(\mathrm{~m}, 22 \mathrm{H}), 1.73-1.82(\mathrm{~m}, 6 \mathrm{H}), 3.88(\mathrm{br}, 4 \mathrm{H}), 4.21$ (br, 2H), 6.76 (br, 4H), 7.12-7.70 (m, 58H), 7.91-8.09 (m, 6H). 
${ }^{13} \mathrm{C} \mathrm{NMR}\left(75 \mathrm{MHz}, \mathrm{CDCl}_{3}\right): \delta 14.01,14.05,14.1,22.6,25.7,27.3$, 29.0, 29.1, 29.2, 29.3, 31.5, 31.7, 43.1, 63.8, 65.2, 67.9, 108.5, $108.6,114.0,114.1,118.6,118.9,119.6,120.4,122.6,122.7,125.5$, $126.2,126.6,126.7,127.1,127.2,127.9,128.2,128.3,128.8,129.1$, 129.6, 132.9, 134.2, 136.0, 136.4, 136.9, 137.6, 137.7, 139.4, 140.3, 140.4, 140.5, 140.6, 141.2, 142.3, 146.6, 151.4, 151.6, 158.0.

Model Compound 5. Aqueous $\mathrm{K}_{2} \mathrm{CO}_{3}(2.0 \mathrm{M}, 1.8 \mathrm{~mL})$ and Aliquat 336 (ca. $200 \mathrm{mg}$ ) were added to a mixture of M1 (0.30 g, $0.44 \mathrm{mmol})$ and phenylboronic acid $(0.16 \mathrm{~g}, 1.31 \mathrm{mmol})$ in toluene (3.62 mL). The mixture was degassed, and then tetrakis(triphenylphosphine)palladium (5 mg) was added in one portion under $\mathrm{N}_{2}$; the solution was heated at $100{ }^{\circ} \mathrm{C}$ for $24 \mathrm{~h}$ before being cooled and extracted with EtOAc $(3 \times 100 \mathrm{~mL})$. The combined organic layers were dried $\left(\mathrm{MgSO}_{4}\right)$ and concentrated under reduced pressure. The crude product was purified through column chromatography (EtOAc/hexane, 1:100) to afford the model compound $5(0.22 \mathrm{~g}$, $74.5 \%)$ as a white solid. ${ }^{1} \mathrm{H}$ NMR $\left(300 \mathrm{MHz}, \mathrm{CDCl}_{3}\right): \delta 0.88(\mathrm{t}, J$ $=7.2 \mathrm{~Hz}, 6 \mathrm{H}), 1.25-1.44(\mathrm{~m}, 12 \mathrm{H}), 1.68-1.76(\mathrm{~m}, 4 \mathrm{H}), 3.89(\mathrm{t}$, $J=6.6 \mathrm{~Hz}, 4 \mathrm{H}), 6.77(\mathrm{~d}, J=8.7 \mathrm{~Hz}, 4 \mathrm{H}), 7.17(\mathrm{~d}, J=8.7 \mathrm{~Hz}$, $4 \mathrm{H}), 7.33-7.38(\mathrm{~m}, 2 \mathrm{H}), 7.44-7.52(\mathrm{~m}, 8 \mathrm{H}), 7.66(\mathrm{~d}, J=8.1 \mathrm{~Hz}$, $4 \mathrm{H}), 8.00(\mathrm{~s}, 2 \mathrm{H}) .{ }^{13} \mathrm{C} \mathrm{NMR}\left(75 \mathrm{MHz}, \mathrm{CDCl}_{3}\right): \delta$ 14.0, 22.6, 25.7, 29.2, 31.6, 63.8, 67.9, 114.1, 118.8, 126.3, 127.1, 127.2, 128.8, 129.1, 137.7, 140.1, 140.6, 141.3, 151.3, 157.9.

Model Compound 6. Eaton's reagent $(0.25 \mathrm{~mL})$ was added dropwise at $25{ }^{\circ} \mathrm{C}$ under a nitrogen atmosphere to a solution of 9-ethylcarbazole (1.17 g, $6.00 \mathrm{mmol})$ and 9-phenyl-9-fluorenol (0.78 $\mathrm{g}, 3.02 \mathrm{mmol})$ in $\mathrm{CH}_{2} \mathrm{Cl}_{2}(20 \mathrm{~mL})$. The color of the solution changed to greenish-blue immediately. Stirring was continued for $1 \mathrm{~h}$, and then the reaction mixture was washed sequentially with water (3 $\times 30 \mathrm{~mL})$, dilute aqueous $\mathrm{NaHCO}_{3}(1 \times 30 \mathrm{~mL})$, and brine $(2 \times$ $30 \mathrm{~mL}$ ). The aqueous layers were each back-extracted with $\mathrm{CH}_{2} \mathrm{Cl}_{2}$ $(2 \times 30 \mathrm{~mL})$. The combined organic layers were dried $\left(\mathrm{MgSO}_{4}\right)$ and the solvent evaporated under vacuum to provide a crude product $(2.21 \mathrm{~g})$ that was subjected to flash chromatography $\left(\mathrm{SiO}_{2}\right.$; $n$-hexane/EtOAc, gradient elution). The yellow solid obtained was recrystallized ( $n$-hexane/ $\mathrm{CH}_{2} \mathrm{Cl}_{2}$ ) to yield the model compound $\mathbf{6}$ (0.96 g, 73.0\%). ${ }^{1} \mathrm{H}$ NMR (300 MHz, $\left.\mathrm{CDCl}_{3}\right): \delta 1.30$ (t, $J=7.2$ $\mathrm{Hz}, 3 \mathrm{H}), 4.18(\mathrm{q}, J=7.2 \mathrm{~Hz}, 2 \mathrm{H}), 7.06-7.38(\mathrm{~m}, 14 \mathrm{H}), 7.47(\mathrm{~d}$, $J=7.5 \mathrm{~Hz}, 2 \mathrm{H}), 7.75(\mathrm{~d}, J=7.8 \mathrm{~Hz}, 2 \mathrm{H}), 7.87(\mathrm{~d}, J=7.8 \mathrm{~Hz}$, $1 \mathrm{H}), 7.89(\mathrm{~d}, J=2.1 \mathrm{~Hz}, 1 \mathrm{H}) .{ }^{13} \mathrm{C}$ NMR $\left(75 \mathrm{MHz}, \mathrm{CDCl}_{3}\right): \delta$ $13.8,37.4,65.5,108.1,108.3,118.6,119.6,120.1,120.4,122.5$, $122.8,125.5,125.9,126.3,126.5,127.3,127.6,127.6,128.1,128.2$, $136.3,138.8,140.0,146.7,151.9$. MS $(\mathrm{m} / \mathrm{z}):[\mathrm{M}]^{+}$calcd for $\mathrm{C}_{33} \mathrm{H}_{25} \mathrm{~N}$, 435; found, 435 .

\section{Results and Discussion}

Synthesis of Monomers and Polymers. As indicated in Scheme 1, the acid-catalyzed condensation of 3,6-dibromo-9fluorenone (1) with excess phenol gave 9,9-bis(4-hydroxyphenyl)-3,6-dibromofluorene (2). Subsequent alkylation of $\mathbf{2}$ with 1-bromohexane through a Williamson ether synthesis afforded the desired monomer M1. Meanwhile, the carbazole-containing monomer M2 was prepared through a Grignard reaction between $\mathbf{1}$ and phenylmagnesium bromide followed by an acid-mediated Friedel-Crafts-type substitution reaction with 9-octyl-9Hcarbazole at the electron-rich carbon atom of the carbazole ring. The tetraphenylsilane diboronate $\mathbf{M 3}$ was synthesized from a dibromo precursor and the commercially available bis(pinacolato)diboron under palladium catalysis in a mixture of anhydrous DMF and $\mathrm{CH}_{3} \mathrm{COOK}$. With the monomers M1-M3 in hand, the alternating copolymers P1 and P2 were obtained through Suzuki polycondensations of various monomer mixtures (Scheme 2 ). The synthesized monomers and the resulting copolymers were characterized using ${ }^{1} \mathrm{H}$ and ${ }^{13} \mathrm{C}$ NMR spectroscopy and MS spectrometry. On the basis of the integrations of the aliphatic protons $\left(-\mathrm{O}-\mathrm{CH}_{2}-\right.$ and $-\mathrm{N}-\mathrm{CH}_{2}-$ at 3.88 and $4.21 \mathrm{ppm}$, respectively), the composition of monomers $\mathbf{1}$ and $\mathbf{2}$ present in the copolymer P2was estimated as 1.0:1.0, which matched very well with the feed ratio.
Scheme 1. Synthetic Route of Monomers and Chemical Structures of Model Compounds ${ }^{a}$

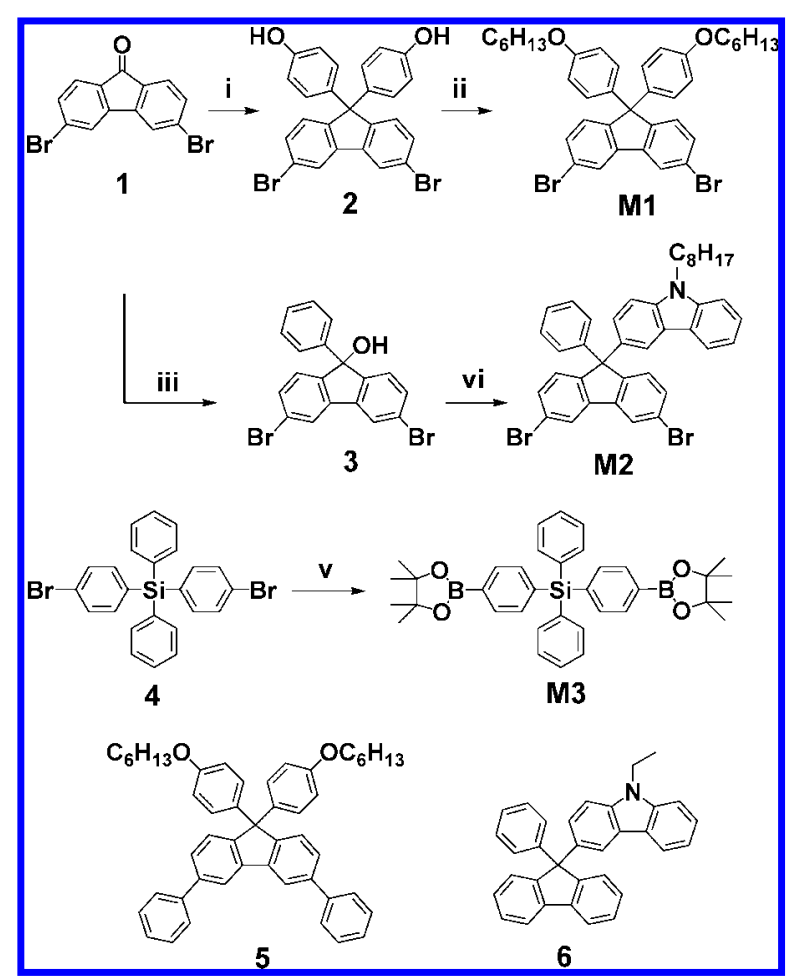

${ }^{a}$ Reagents: (i) phenol $/ \mathrm{CH}_{3} \mathrm{SO}_{3} \mathrm{H} / \mathrm{CCl}_{4}$; (ii) 1-bromohexane $/ \mathrm{K}_{2} \mathrm{CO}_{3} /$ DMF; (iii) $\mathrm{PhMgBr} / \mathrm{Et}_{2} \mathrm{O}$; (iv) 9-octyl-9H-carbazole/Eaton's reagent/ $\mathrm{CH}_{2} \mathrm{Cl}_{2}$; (v) bis(pinacolato) diboron/ $\mathrm{PdCl}_{2}(\mathrm{dppf}) / \mathrm{CH}_{3} \mathrm{COOK} / \mathrm{DMF}$.

Scheme 2. Synthesis of Copolymers P1 and $\mathbf{P 2}^{a}$

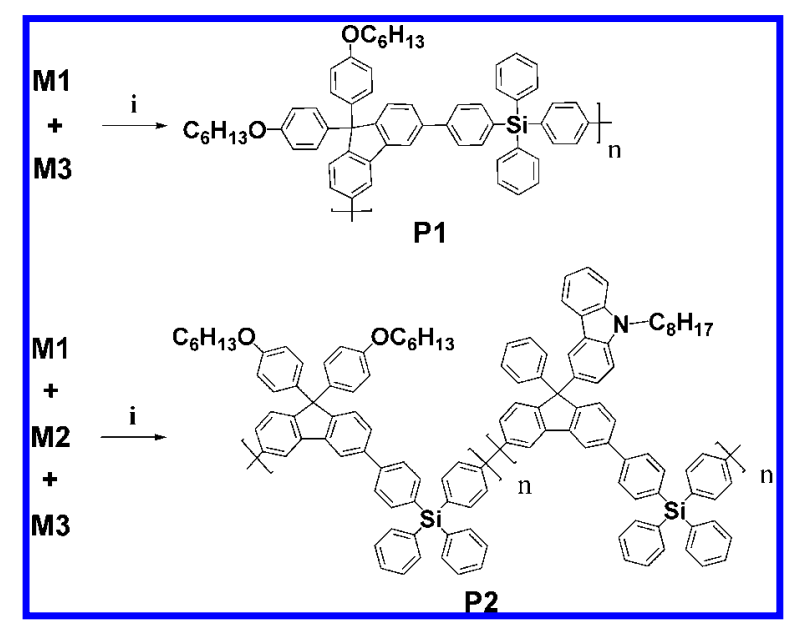

${ }^{a}$ Reagents: (i) $\mathrm{Pd}\left(\mathrm{PPh}_{3}\right)_{4} / \mathrm{K}_{2} \mathrm{CO}_{3} /$ Aliquat 336/toluene/ $\mathrm{H}_{2} \mathrm{O}$.

The fluorene-based copolymers $\mathbf{P 1}$ and $\mathbf{P 2}$ are readily soluble in common organic solvents, including toluene, chlorobenzene, chloroform, and THF. The weight-average molecular weights $\left(M_{\mathrm{w}}\right)$ of $\mathbf{P 1}$ and $\mathbf{P 2}$, as determined through gel permeation chromatography (GPC) using polystyrenes as standards, were $1.6 \times 10^{4}$ and $1.3 \times 10^{4} \mathrm{~g} \mathrm{~mol}^{-1}$, respectively, with polydispersities of 1.5 and 1.3, respectively. The thermal properties of $\mathbf{P 1}$ and $\mathbf{P 2}$ were investigated through thermogravimetric analysis (TGA) and differential scanning calorimetry (DSC). P1 and P2 exhibited outstanding thermal stability, with their 5\% weight losses occurring at temperatures of 433 and $456{ }^{\circ} \mathrm{C}$, respectively. As indicated in Figure 1, distinct glass transitions appeared at 217 and $215^{\circ} \mathrm{C}$ for $\mathbf{P 1}$ and $\mathbf{P 2}$, respectively. It is evident that the incorporation of the rigid and bulky tetraphenylsilane units 


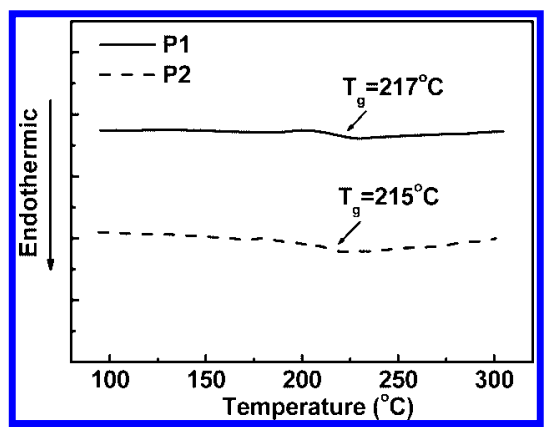

Figure 1. Differential scanning calorimetry (DSC) traces of $\mathbf{P 1}$ and $\mathbf{P 2}$ recorded at a heating rate of $20^{\circ} \mathrm{C} / \mathrm{min}$.

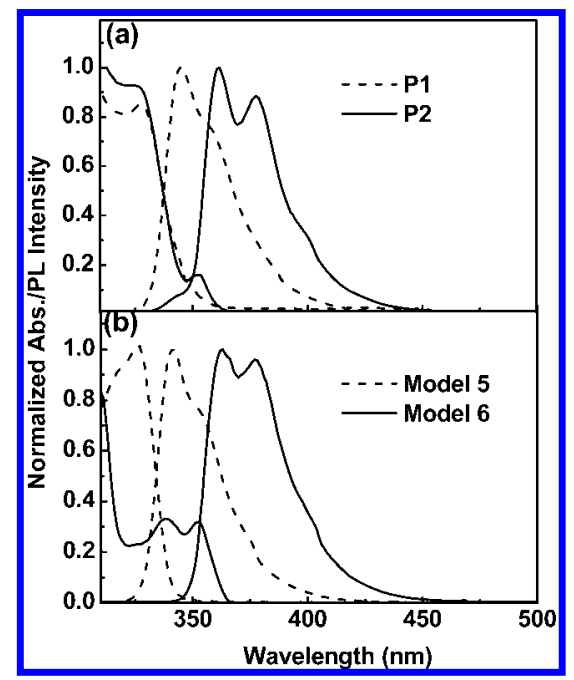

Figure 2. UV-vis absorption and PL spectra (excited at $300 \mathrm{~nm}$ ) of dilute THF solutions of (a) $\mathbf{P 1}$ and $\mathbf{P 2}$ and (b) model compounds $\mathbf{5}$ and $\mathbf{6}$.

Table 1. Optical Properties of P1, P2, and Model Compounds 5 and 6

\begin{tabular}{|c|c|c|c|c|c|}
\hline & \multicolumn{2}{|c|}{ absorption, $\lambda_{\max }(\mathrm{nm})$} & \multicolumn{2}{|c|}{$\mathrm{PL}, \lambda_{\max }(\mathrm{nm})$} & \multirow[b]{2}{*}{$\Phi_{\mathrm{f}}^{a, c}$} \\
\hline & solution $^{a}$ & film $^{b}$ & solution $^{a}$ & film $^{b}$ & \\
\hline P1 & 328 & 329 & 346 & 352 & 0.57 \\
\hline P2 & 325,353 & 327,354 & 362,378 & 369,381 & 0.53 \\
\hline 5 & 328 & & 341 & & \\
\hline 6 & 337,353 & & 363,377 & & \\
\hline
\end{tabular}

${ }^{a}$ In THF. ${ }^{b}$ Spin-coated from $\mathrm{CHCl}_{3}$ solutions. ${ }^{c}$ Relative quantum yield was measured with reference to $p$-terphenyl in 1,2 -dichloroethane $(\Phi=$ $0.91)$.

enhanced the chain rigidity of the polymers and resulted in the high values of $T_{\mathrm{g}}{ }^{47}$ which we expected would suppress any morphological changes from occurring upon exposure to heat-a desirable characteristic for polymers used as host materials in light-emitting applications. ${ }^{48}$

Photophysical Properties. To examine their photophysical properties, the absorption and photoluminescence (PL) spectra of P1, P2, and the model compounds 5 and $\mathbf{6}$ were measured from dilute solutions (Figure 2); Table 1 summarizes the spectral data. P1 exhibits a major absorption at $328 \mathrm{~nm}$ in THF, whereas $\mathbf{P} 2$ reveals its main absorption peak at $325 \mathrm{~nm}$ with a longer wavelength absorption at ca. $353 \mathrm{~nm}$. From a comparison with the absorption spectra of the model compounds $\mathbf{5}$ and $\mathbf{6}$, we ascribe the band at ca. $325 \mathrm{~nm}$ to a $\pi-\pi^{*}$ transition arising from the 3,6-diphenylfluorene segment and the band at ca. 353 $\mathrm{nm}$ to absorptions of the pendent carbazole groups. The absorption maxima of $\mathbf{P 1}$ and $\mathbf{P 2}$ are considerably blue-shifted relative to those of unmodified PFs and are very close to that of model compound $\mathbf{5}$ (328 nm), indicating successful confine-

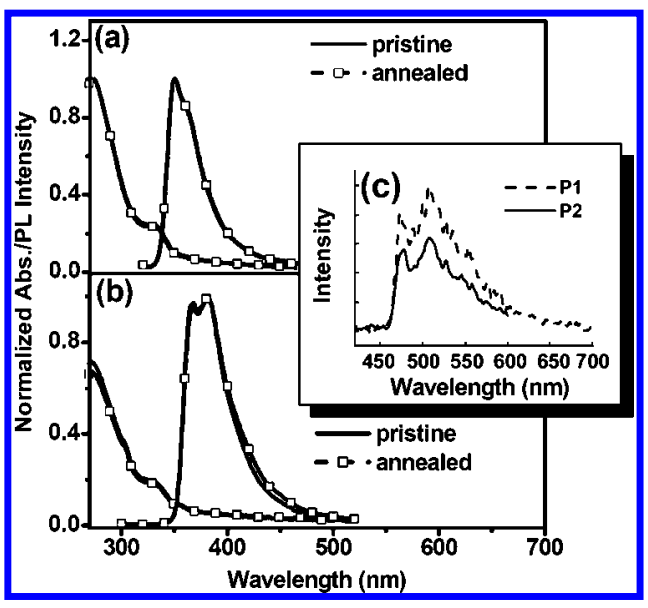

Figure 3. UV-vis absorption and PL spectra (excited at $300 \mathrm{~nm}$ ) of (a) $\mathbf{P 1}$ and (b) $\mathbf{P 2}$ films, recorded before and after annealing at $150{ }^{\circ} \mathrm{C}$ for $20 \mathrm{~h}$ in air. (c) Phosphorescence spectra of P1 and P2 films at $77 \mathrm{~K}$.

ment of the polymers' effective conjugation lengths as a result of the $\delta$-Si atoms positioned in the polymer backbones; ${ }^{47,49}$ in addition, the conjugation paths in the copolymers were further limited by the presence of 3,6-linkages of the fluorene units. ${ }^{33,34}$ Upon excitation, the emission spectrum of P1 displays an emission band at $346 \mathrm{~nm}$, which is identical behavior to that of the model compound 5. On the other hand, $\mathbf{P 2}$ exhibits two vibronic peaks at 362 and $378 \mathrm{~nm}$; we detected almost no luminescence from the 3,6-disubstituted fluorene unit (model compound 5). The appearance of the PL spectrum of P2, which is nearly identical to that of the model compound $\mathbf{6}$, can be attributed to emission from the pendent carbazole groups. This observation suggests that energy transfer from the excited fluorene units to the pendant carbazole groups is efficient. The PL quantum yields of polymers $\mathbf{P 1}$ and $\mathbf{P 2}$ in 1,2-dichloroethane were 0.57 and 0.53 , respectively, when using $p$-terphenyl $\left(\Phi_{\mathrm{f}}\right.$ $=0.91$ ) as a standard. ${ }^{33}$

Figure 3 presents the absorption and PL spectra of $\mathbf{P 1}$ and P2 films spin-coated from chlorobenzene solution onto a quartz plate. Relative to the spectra obtained from the dilute solutions, the absorption signals of the thin films were slightly broadened, with the emission spectra displaying red shifts for polymers P1 and $\mathbf{P 2}$ of 6 and $7 \mathrm{~nm}$, respectively (i.e., peaks at 352 and 369 $\mathrm{nm}$, respectively). Thin films of PF exhibit poor spectral stability upon exposure to heat; the cause of this undesirable emissive color instability has been attributed to the formation of aggregates and interchain excimers or to keto defects. ${ }^{50-52}$ To examine the emission color stabilities of $\mathbf{P 1}$ and $\mathbf{P 2}$, their polymer films were baked for $20 \mathrm{~h}$ on a hot plate at $150{ }^{\circ} \mathrm{C}$ in air. As indicated in Figure 3, the absorption and PL spectra of both polymers remained virtually unchanged after this thermal treatment. In addition to the DSC data, this result provides further evidence for the high thermal stabilities of P1 and P2, which were improved significantly over that of $\mathrm{PF}$ as a result of the incorporation of tetraphenylsilane units at the 3- and 6-positions of the PF backbone and diphenyl substituents at the C-9 position.

Figure $3 c$ displays the phosphorescence spectra of the $\mathbf{P 1}$ and $\mathbf{P 2}$ polymer films measured at $77 \mathrm{~K}$. The triplet energy gaps of $\mathbf{P 1}$ and $\mathbf{P 2}$ were calculated relative to the highest-energy triplet vibronic transition located at ca. $2.60 \mathrm{eV}$, giving values significant higher than those of commonly used PFs $(2.15$ $\mathrm{eV}){ }^{24,28}$ In fact, the values of $E_{\mathrm{T}}$ of $\mathbf{P 1}$ and $\mathbf{P 2}$ match that of 4,4'-bis(9-carbazolyl)biphenyl (CBP, $2.56 \mathrm{eV}$ ), which is a prominent host for triplet emitters in small-molecule OLEDs. ${ }^{10}$ A higher value of $E_{\mathrm{T}}$ for the host material is a provision allowing the effective confinement of triplet excitons on the guest, which, 


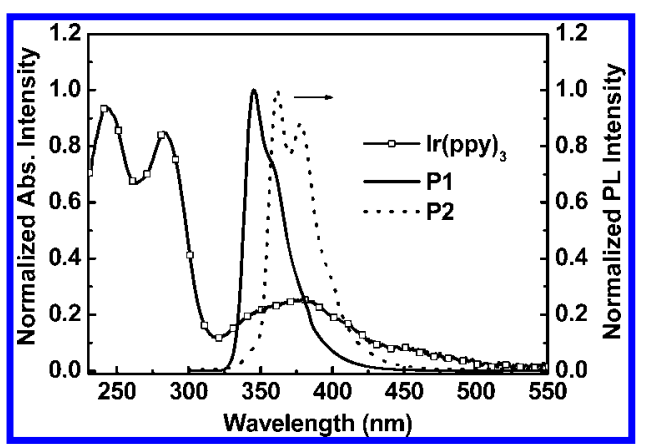

Figure 4. PL spectra of $\mathbf{P 1}$ and $\mathbf{P 2}$ films (excited at $300 \mathrm{~nm}$ ) and the absorption spectrum of $\operatorname{Ir}(\mathrm{ppy})_{3}$ in THF solution.

consequently, prevents back energy transfer between the host and dopant molecule. ${ }^{53,54}$ In this case, the values of $E_{\mathrm{T}}$ are sufficiently high, allowing $\mathbf{P 1}$ and $\mathbf{P 2}$ to serve as appropriate hosts for green-emitting dopants, such as fac-tris(2-phenylpyridine)iridium $\left[\operatorname{Ir}(\mathrm{ppy})_{3}\right](2.41 \mathrm{eV})$, and other long-wavelength dopants.

Electrochemical Studies. We employed cyclic voltammetry (CV) to investigate the oxidation behavior of $\mathbf{P 1}$ and $\mathbf{P 2}$ and to estimate their HOMO energy levels. The electrochemical processes of these polymer films coated on glassy carbon electrodes were monitored in a standard three-electrode electrochemical cell, using ferrocene as the internal standard, in an electrolyte of $0.1 \mathrm{M}$ tetrabutylammonium hexafluorophosphate $\left(\mathrm{TBAPF}_{6}\right)$ in acetonitrile, at a scanning rate of $50 \mathrm{mV} / \mathrm{s}$. The polymers $\mathbf{P 1}$ and $\mathbf{P 2}$ exhibited oxidation onset potentials at ca. 1.11 and $0.91 \mathrm{eV}$, respectively; thus, we estimated their HOMO energy levels to be -5.91 and $-5.71 \mathrm{eV}$, respectively, with regard to the energy level of ferrocene (4.8 eV below vacuum). In comparison with $\mathbf{P 1}$, the incorporation of carbazole moieties increased the HOMO level of P2 markedly; its higher-lying HOMO level might have originated from the electron-rich nature of the carbazole ring, in agreement with data reported previously for PF copolymers containing pendent carbazole groups. ${ }^{45}$ As a result, we expected that the hole injection barrier for polymer $\mathbf{P 2}$ at the interface with an ITO/PEDOT anode would be significantly better than that of polymer P1. Because we were unable to observe the reduction processes of the polymers, we deduced the corresponding LUMO levels of P1 and P2 from their HOMO levels and optical band gaps.

Electroluminescence Properties of PLED Devices. To evaluate the potential of $\mathbf{P 1}$ and $\mathbf{P 2}$ for use as polymeric host materials, we fabricated green-electrophosphorescent devices using $\operatorname{Ir}(\text { ppy })_{3}$, as the emitter, blended with P1 and P2, respectively. A typical multilayer architecture comprised ITO/ PEDOT/host: 7 wt \% Ir(ppy) 3 (40 nm)/TPBI (40 nm)/LiF (1 $\mathrm{nm}) / \mathrm{Al}(100 \mathrm{~nm})$, where the hosts were P1 for device I and $\mathbf{P 2}$ for device II. Figure 4 displays the normalized UV-vis absorption spectrum of $\operatorname{Ir}(\mathrm{ppy})_{3}$ in THF solution and the PL spectra of polymers $\mathbf{P 1}$ and $\mathbf{P 2}$. There is a significant overlap between the signals in the PL spectra of both polymers and the metal-to-ligand charge transfer (MLCT) absorption band at 370 $\mathrm{nm}$ of $\operatorname{Ir}(\mathrm{ppy})_{3}$. This finding implies that an efficient Förstertype energy transfer might occur from the excited singlet state of the host to the MLCT state of $\operatorname{Ir}(\mathrm{ppy})_{3}$, followed by fast intersystem crossing and, subsequently, emission from its triplet excited state. ${ }^{55}$ Consequently, as indicated in Figure 5, the PL spectra of the $\operatorname{Ir}(\text { ppy })_{3}$-doped $\mathbf{P 1}$ and $\mathbf{P 2}$ films exhibit emissions arising mainly from $\operatorname{Ir}(\mathrm{ppy})_{3}$ at $512 \mathrm{~nm}$, together with a minor contribution from the host. On the other hand, the EL spectra of these blends exhibited only the green emission derived from $\operatorname{Ir}(\text { ppy })_{3}$, suggesting that both energy transfer and direct charge trapping/recombination at the $\operatorname{Ir}(\mathrm{ppy})_{3}$ guest were responsible

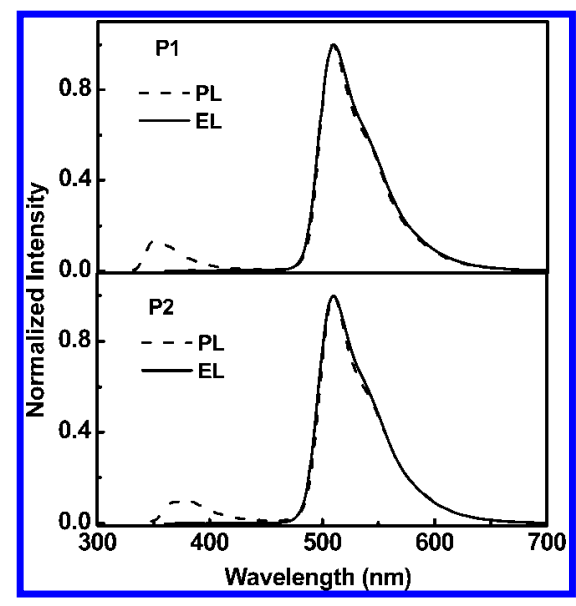

Figure 5. PL (excited at $320 \mathrm{~nm}$ ) and EL spectra of (a) the $\operatorname{Ir}(\mathrm{ppy})_{3^{-}}$ doped P1 film and (b) the $\operatorname{Ir}(\mathrm{ppy})_{3}$-doped P2film.



Figure 6. Plots of current density vs voltage for devices I and II. Inset: energy level diagram for devices having the configuration ITO/PEDOT/ Blend/TPBI/LiF/Al.

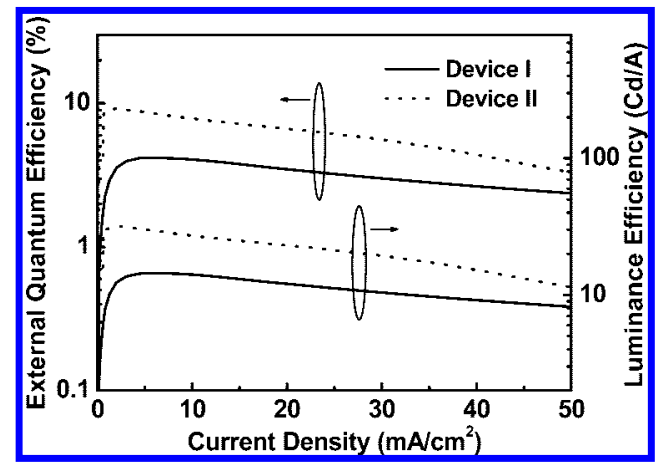

Figure 7. External quantum efficiency and luminance efficiency plotted with respect to the current density for devices I and II.

for the observed EL. ${ }^{28,56}$ Figure 6 displays the current density vs voltage $(I-V)$ characteristics of devices I and II. It is evident that the driving voltage of device II was lower than that of the corresponding device I, presumably because of the facilitated hole injection and transportation in device II. According to the energy level diagram (inset to Figure 6), the lower ionization potential of $\mathbf{P 2}(\mathrm{HOMO}=5.7 \mathrm{eV})$ matches the work function of the ITO/PEDOT electrode better than that of P1. Thus, holes can be injected from the anode into the HOMO level of $\mathbf{P 2}$ more effectively than into that of P1. Figure 7 presents the EL performances of these two devices; Table 2 summarizes the data. Device II exhibited a maximum external quantum efficiency $\left(\max \eta_{\text {ext }}\right)$ of $9.2 \%\left(32.0 \mathrm{~cd} / \mathrm{A}, 1.95 \mathrm{~mA} / \mathrm{cm}^{2}\right)$-2-fold higher than that of device I, which had a value of max $\eta_{\text {ext }}$ of $4.2 \%$ $\left(14.5 \mathrm{~cd} / \mathrm{A}, 6.22 \mathrm{~mA} / \mathrm{cm}^{2}\right)$. We attribute the pronounced improvement in device II's performance to several factors: (1) the smaller barrier for hole injection from the ITO/PEDOT 
Table 2. Performance of Devices Having the Structure ITO/ PEDOT/Polymer Emitting Layer/TPBI/LiF/Al

\begin{tabular}{|c|c|c|}
\hline & P1: $\operatorname{Ir}(\mathrm{ppy})_{3}$ & P2: Ir (ppy) 3 \\
\hline turn-on voltage $(\mathrm{V})^{a}$ & 9.49 & 7.99 \\
\hline voltage $(\mathrm{V})^{b}$ & 17.0 & 14.2 \\
\hline brightness $\left(\mathrm{cd} / \mathrm{m}^{2}\right)^{b}$ & 2415 & 4581 \\
\hline luminance efficiency $(\mathrm{cd} / \mathrm{A})^{b}$ & 12.1 & 23.1 \\
\hline external quantum efficiency $(\%)^{b}$ & 3.5 & 6.7 \\
\hline $\begin{array}{l}\text { maximum luminance efficiency } \\
(\mathrm{cd} / \mathrm{A})\end{array}$ & 14.5 & 32.0 \\
\hline $\begin{array}{l}\text { maximum external quantum } \\
\text { efficiency }(\%)\end{array}$ & 4.2 & 9.2 \\
\hline EL maximum $(\mathrm{nm})^{c}$ & 512 & 512 \\
\hline CIE coordinates, ${ }^{c} x$ and $y$ & 0.24 and 0.65 & 0.24 and 0.65 \\
\hline
\end{tabular}

${ }^{a}$ Recorded at $1 \mathrm{~cd} / \mathrm{m}^{2} .{ }^{b}$ Recorded at $20 \mathrm{~mA} / \mathrm{cm}^{2} .{ }^{c}$ Recorded at $11 \mathrm{~V}$.

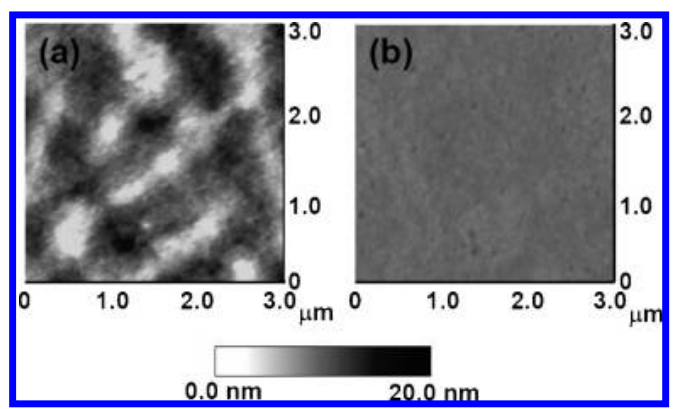

Figure 8. AFM topographic images (tapping mode) of $\operatorname{Ir}(\mathrm{ppy})_{3}$-doped (7 wt \%) (a) P1 and (b) P2 films. These films had been spin-coated on a quartz substrate.

electrode to the emitting layer; (2) the better match between the hole- and electron-injection barriers $(0.5$ and $0.4 \mathrm{eV}$ for device II; cf. 0.7 and $0.3 \mathrm{eV}$ for device I); (3) the ambipolar nature of the carbazole group, which can promote both hole and electron fluxes $;{ }^{57}$ and (4) the suppression of phase separation or aggregation in the P2-based blend. We used atomic force microscopy (AFM) to investigate the phase morphologies of both blend systems. Figure 8 displays the surface topographies of the $\operatorname{Ir}(\mathrm{ppy})_{3}$-doped (7 wt \%) polymer films. The topographic image of the P2-based film is smooth and featureless with a root-mean-square (rms) surface roughness of $0.54 \mathrm{~nm}$, indicating that the film was homogeneous with no phase separation or aggregation. In contrast, the P1-based film displayed obvious hill-like patterns; its rms surface roughness was $3.09 \mathrm{~nm}$, which is almost 6-fold higher than that of the P2-based blend. These AFM images suggest that the structure of the carbazolecontaining P2 might provide a compatible environment in which the phosphorescent emitters are isolated and dispersed homogeneously. Therefore, the degree of self-quenching arising from aggregation was significantly diminished in the $\mathbf{P} 2$ host, with the resulting green-emitting device yielding a greater improvement in device efficiency relative to that of the P1-based device. To the best of our knowledge, the performance of device II is among the highest for such green-emitting electrophosphorescent devices incorporating fluorene- or carbazole-based copolymers as polymeric hosts in the absence of additional electron transporting materials blended into the active layer. ${ }^{30,31,33,34}$

\section{Conclusions}

We have fabricated highly efficient green phosphorescent PLEDs incorporating the polymeric host P2, which we synthesized through copolymerization of monomers containing tetraphenylsilane and 3,6-disubstituted fluorene frameworks, respectively. The conjugation length of polymer $\mathbf{P 2}$ was effectively confined through the presence of 3,6-linkages and silane atoms in the polymer skeleton; consequently, the singlet and triplet energies of $\mathbf{P 2}$ were significantly higher than those of conven- tional PF derivatives. In addition, pendent carbazole groups were functionalized directly onto the C-9 positions of the alternating fluorene units to reduce the hole-injection barrier, balance charge fluxes, and enhance the compatibility with Ir-based triplet emitters. As a result, we obtained highly efficient green-emitting PLEDs when we employed $\mathbf{P 2}$ doped with fac-tris(2-phenylpyridine)iridium as the host material. The maximum values of the external quantum and luminance efficiencies of the P2-based green-emitting device reached $9.2 \%$ and $32 \mathrm{~cd} / \mathrm{A}$, respectively, at a current density of $1.95 \mathrm{~mA} / \mathrm{cm}^{2}$. Even when the brightness was elevated to $1000 \mathrm{~cd} / \mathrm{m}^{2}$, the corresponding efficiency remained above $30 \mathrm{~cd} / \mathrm{A}$.

Acknowledgment. We thank the National Science Council for financial support. Our special thanks go to Professor C.-H. Cheng for his support during the preparation and characterization of the light-emitting devices.

\section{References and Notes}

(1) Kido, J.; Kimura, M.; Nagai, K. Science 1995, 267, 1332.

(2) Tasch, S.; List, E. J. W.; Ekström, O.; Graupner, W.; Leising, G.; Schlichting, P.; Rohr, U.; Geerts, Y.; Scherf, U.; Müllen, K. Appl. Phys. Lett. 1997, 71, 2883.

(3) Burroughes, J. H.; Bradley, D. D. C.; Brown, A. R.; Marks, R. N.; Mackay, K.; Friend, R. H.; Burns, P. L.; Holmes, A. B. Nature (London) 1990, 347, 539.

(4) Kraft, A.; Grimsdale, A. C.; Holmes, A. B. Angew. Chem. Int. Ed. 1998, 37, 402.

(5) Friend, R. H.; Gymer, R. W.; Holmes, A. B.; Burroughes, J. H.; Marks, R. N.; Taliani, C.; Bradley, D. D. C.; Dos Santos, D. A.; Brédas, J. L.; Lögdlund, M.; Salaneck, W. R. Nature (London) 1999, 397, 121.

(6) Bernius, M. T.; Inbasekaran, M.; O’Brien, J.; Wu, W. Adv. Mater. 2000, 12, 1737.

(7) Turro, N. J. Modern Molecular Photochemistry; University Science Books: Sausalito, CA, 1991.

(8) Adachi, C.; Baldo, M. A.; Thompson, M. E.; Forrest, S. R. Appl. Phys. 2001, 90, 5048.

(9) Kawamura, Y.; Goushi, K.; Brooks, J.; Brown, J. J.; Sasabe, H.; Adachi, C. Appl. Phys. Lett. 2005, 86, 071104.

(10) Lamansky, S.; Djurovich, P.; Murphy, D.; Abdel-Razzaq, F.; Lee, H. E.; Adachi, C.; Burrows, P. E.; Forrest, S. R.; Thompson, M. E. J. Am. Chem. Soc. 2001, 123, 4304.

(11) Kido, J.; Shionoya, H.; Nagai, K. Appl. Phys. Lett. 1995, 67, 2281.

(12) McGehee, M. D.; Bergstedt, T.; Zhang, C.; Saab, A. P.; O'Regan, M. B.; Bazan, G. C.; Srdanov, V. I.; Heeger, A. J. Adv. Mater. 1999, 11,1349 .

(13) Gong, X.; Robinson, M. R.; Ostrowski, J. C.; Moses, D.; Bazan, G. C.; Heeger, A. J. Adv. Mater. 2002, 14, 581.

(14) Kim, J. H.; Liu, M. S.; Jen, A. K. Y.; Carlson, B.; Dalton, L. R.; Shu, C. F.; Dodda, R. Appl. Phys. Lett. 2003, 83, 776.

(15) Wu, F. I.; Shih, P. I.; Shu, C. F.; Tung, Y. L.; Chi, Y. Macromolecules 2005, 38, 9028 .

(16) Yuan, M. C.; Shih, P. I.; Chien, C. H.; Shu, C. F. J. Polvm. Sci., Part A: Polvm. Chem. 2007, 45, 2925.

(17) Gong, X.; Ostrowski, J. C.; Bazan, G. C.; Moses, D.; Heeger, A. J. Appl. Phys. Lett. 2002, 81, 3771.

(18) Gong, X.; Ostrowski, J. C.; Moses, D.; Bazan, G. C.; Heeger, A. J. Adv. Funct. Mater. 2003, 13, 439.

(19) Tanaka, I.; Suzuki, M.; Tokito, S. Jpn. J. Appl. Phys. 2003, 42, 2737.

(20) Shih, P. I.; Shu, C. F.; Tung, Y. L.; Chi, Y. Appl. Phys. Lett. 2006, $88,251110$.

(21) Yang, X.; Müller, D. C.; Neher, D.; Meerholz, K. Adv. Mater. 2006, $18,948$.

(22) Yang, X.; Neher, D.; Hertel, D.; Däubler, T. K. Adv. Mater. 2004, $16,161$.

(23) Janietz, S.; Bradley, D. D. C.; Grell, M.; Giebeler, C.; Inbasekaran, M.; Woo, E. P. Appl. Phys. Lett. 1998, 73, 2453.

(24) Chen, F. C.; He, G.; Yang, Y. Appl. Phys. Lett. 2003, 82, 1006.

(25) Jiang, C.; Yang, W.; Peng, J.; Xiao, S.; Cao, Y. Adv. Mater. 2004, $16,537$.

(26) Wu, F. I.; Shih, P. I.; Tseng, Y. H.; Shu, C. F.; Tung, Y. L.; Chi, Y. J. Mater. Chem. 2007, 17, 167.

(27) Jinsong, H.; Watanabe, T.; Ueno, K.; Yang, Y. Adv. Mater. 2007, 19, 739.

(28) Chen, F. C.; Chang, S. C.; He, G.; Pyo, S.; Yang, Y.; Kurotaki, M.; Kido, J. J. Polvm. Sci., Part B: Polvm. Phys. 2003, 41, 2681.

(29) Sudhakar, M.; Djurovich, P. I.; Hogen-Esch, T. E.; Thompson, M. E. J. Am. Chem. Soc. 2003, 125, 7796. 
(30) Van Dijken, A.; Bastiaansen, J. J. A. M.; Kiggen, N. M. M.; Langeveld, B. M. W.; Rothe, C.; Monkman, A.; Bach, I.; Stössel, P.; Brunner, K. J. Am. Chem. Soc. 2004, 126, 7718.

(31) Chen, Y. C.; Huang, G. S.; Hsiao, C. C.; Chen, S. A. J. Am. Chem. Soc. 2006, 128, 8549 .

(32) Mo, Y.; Jiang, X.; Cao, D. Org. Lett. 2007, 9, 4371.

(33) Mo, Y.; Tian, R.; Shi, W.; Cao, Y. Chem. Commun. 2005, 4925.

(34) Chan, K. L.; Watkins, S. E.; Mak, C. S. K.; McKiernan, M. J.; Towns, C. R.; Pascu, S. I.; Holmes, A. B. Chem. Commun. 2005, 5766.

(35) Ren, X.; Li, J.; Holmes, R. J.; Djurovich, P. I.; Forrest, S. R.; Thompson, M. E. Chem. Mater. 2004, 16, 4743.

(36) Yeh, S. J.; Wu, M. F.; Chen, C. T.; Song, Y. H.; Chi, Y.; Ho, M. H.; Hsu, S. F.; Chen, C. H. Adv. Mater. 2005, 17, 285.

(37) Tsai, M. H.; Lin, H. W.; Su, H. C.; Ke, T. H.; Wu, C. C.; Fang, F. C.; Liao, Y. L.; Wong, K. T.; Wu, C. I. Adv. Mater. 2006, 18, 1216.

(38) Shih, P. I.; Chien, C. H.; Chuang, C. Y.; Shu, C. F.; Yang, C. H.; Chen, J. H.; Chi, Y. J. Mater. Chem. 2007, 17, 1692.

(39) Strohriegl, P.; Grazulevicius, J. V. Adv. Mater. 2002, 14, 1439.

(40) Zhang, Q.; Chen, J.; Cheng, Y.; Wang, L.; Ma, D.; Jing, X.; Wang, F. J. Mater. Chem. 2004, 14, 895 .

(41) Wu, F. I.; Shih, P. I.; Yuan, M. C.; Dixit, A. K.; Shu, C. F.; Chung, Z. M.; Diau, E. W. G. J. Mater. Chem. 2005, 15, 4753.

(42) Li, Y.; Ding, J.; Day, M.; Tao, Y.; Lu, J.; D'iorio, M. Chem. Mater. 2004, 16, 2165

(43) Du, J.; Fang, Q.; Bu, D.; Ren, S.; Cao, A.; Chen, X. Macromol. Rapid Commun. 2005, 26, 1651.

(44) Wu, C. W.; Tsai, C. M.; Lin, H. C. Macromolecules 2006, 39, 4298.
(45) Yuan, M. C.; Shih, P. I.; Chien, C. H.; Shu, C. F. J. Polym. Sci., Part A: Polvm. Chem. 2007, 45, 2925.

(46) Brunner, K.; van Dijken, A.; Börner, H.; Bastiaansen, J. J. A. M.; Kiggen, N. M. M.; Langeveld, B. M. W. J. Am. Chem. Soc. 2004, $126,6035$.

(47) Zhou, X. H.; Niu, Y. H.; Huang, F.; Liu, M. S.; Jen, A. K. Y. Macromolecules 2007, 40, 3015.

(48) Tokito, S.; Tanaka, H.; Noda, K.; Okada, A.; Taga, Y. Appl. Phys. Lett. 1997, 70, 1929.

(49) Liu, X. M.; Xu, J.; Lu, X.; He, C. Macromolecules 2006, 39, 1397.

(50) Teetsov, J.; Fox, M. A. J. Mater. Chem. 1999, 9, 2117.

(51) List, E. J. W.; Guentner, R.; De Freitas, P. S.; Scherf, U. Adv. Mater. 2002, 14, 374.

(52) Bliznyuk, V. N.; Carter, S. A.; Scott, J. C.; Klärner, G.; Miller, R. D.; Miller, D. C. Macromolecules 1999, 32, 361.

(53) Tokito, S.; Iijima, T.; Suzuri, Y.; Kita, H.; Tsuzuki, T.; Sato, F. Appl. Phys. Lett. 2003, 83, 569.

(54) Tanaka, I.; Tabata, Y.; Tokito, S. Chem. Phvs. Lett. 2004, 400, 86.

(55) Colombo, M. G.; Hauser, A.; Güdel, H. Top. Curr. Chem. 1994, 171, 144.

(56) Uchida, M.; Adachi, C.; Koyama, T.; Taniguchi, Y. J. Appl. Phys. 1999, 86, 1680.

(57) Liao, J. L.; Chen, X. W.; Liu, C. Y.; Chen, S. A.; Su, C. H.; Su, A. C. J. Phys. Chem. B 2007, 111, 10379.

MA800391E 